\title{
Pay Attention to This: A Knowledge Translation Study of ADHD and its Brain Basis to Preservice and In-Service Teachers
}

\author{
Kathryn Isenor, ${ }^{1}$ Erin L. Mazerolle, ${ }^{2}$ and Conor Barker ${ }^{3}$ \\ ${ }^{1}$ St. Francis Xavier University \\ ${ }^{2}$ Department of Psychology, St. Francis Xavier University \\ ${ }^{3}$ School of Education, St. Francis Xavier University
}

Authors' Note

Kathryn Isenor (ํ) https://orcid.org/0000-0002-1256-3666

Erin Mazerolle 장 https://orcid.org/0000-0002-2012-8605

Conor Barker $\odot$ https://orcid.org/0000-0003-2977-2832

Correspondence regarding this article should be addressed to Conor Barker, Faculty of Education, St. Francis Xavier University, 4545 Alumni Drive, Antigonish, NS, B2G 2W5. Email $\underline{\text { cbarker@stfx.ca }}$

\begin{abstract}
The purpose of the present study was to develop a knowledge translation (KT) activity for educators about the brain in children and adolescents with attention deficit hyperactivity disorder (ADHD). The goal was to increase our participants' knowledge about ADHD and its brain basis. In addition to neuroscience content, the KT activity included the personal story of the lead researcher's lived experience with ADHD to provide context, and to inform the participants' perceptions of ADHD. Framed in an action research paradigm, our study undertook three cycles of reflection, planning, action, and observation to develop and improve a knowledge translation activity. The knowledge translation activity was presented to 48 preservice and in-service teachers and members of the public across Canada, with a mixed methods approach to evaluate the outcomes. The findings demonstrated that this knowledge translation activity was effective in enhancing participant knowledge about ADHD. Quantitively, a non-significant trend was observed that participants shifted their perceptions from social and behavioural causes to brainbased causes of ADHD. Qualitatively, the participants indicated making connections between the personal story and neuroscience. Effective KT requires a review of context vocabulary and opportunity for teacher interaction. Teachers are aware of several behavioural management strategies but do not have a clear idea of how or why they work. Teaching neuroscience to teachers allows for a discussion of neurodiversity and a strength-based approach to programming and accommodation. This research could help guide future knowledge translation research into the benefits of combining personal lived experience with neuroscience content.
\end{abstract}

Keywords: knowledge translation, neuroscience, attention deficit hyperactivity disorder, lived experience, storytelling, action research, neurodiversity 


\section{Pay Attention to This: A Knowledge Translation Study of ADHD and its Brain Basis to Preservice and In-Service Teachers}

Attention deficit hyperactivity disorder (ADHD) is a neurodevelopmental disorder that can affect an individuals' performance in educational, occupational, and social situations (American Psychiatric Association [APA], 2013). An individual with ADHD may present with hyperactive symptoms (e.g., has difficulty sitting still, difficulty managing impulses), inattentive symptoms (e.g., often does not seem to listen when spoken to directly, often losing track of time or possessions), or a combination of both (APA, 2013). Advances in neuroscience have demonstrated that there are distinct differences in neural anatomy and neural processing among children with ADHD compared to typically developing children (Boon, 2020; Kasparek et al., 2015; Uddin et al., 2017). Scuitto et al. (2000) found that while teachers may know the signs and symptoms of ADHD, they are less versed in the course and treatment of ADHD. Teacher knowledge regarding ADHD-specific intervention is limited, and mainly low-intensity interventions are implemented in classrooms (e.g., preferred seating, body breaks, sticker charts) (Wesney, 2020). Teachers, thus, may be familiar with behavioural presentations of ADHD but may be unsure of how to best support their students using evidence-based practices.

Across Canada, the prevalence of ADHD is on the rise, from about 3\% of 10-14-yearolds being diagnosed in 1999, to about 5\% being diagnosed in 2012 (Vasiliadis et al., 2017). Students with ADHD are less likely to enroll in post-secondary education than both their neurotypical peers and youth with other mental health conditions (Statistics Canada, 2019). Children with ADHD face barriers that their peers do not, such as a lack of adequate support in transition periods (e.g., from elementary to secondary school, from high school to postsecondary) as well as lower parental expectations; in fact, the latter is so impactful, it has been shown to explain the differences between post-secondary education attendance between students with ADHD and other youth (Statistics Canada, 2019).

Boon (2020) has advocated for a systematic update in the professional development for preservice and in-service teachers to better support students with ADHD. Specifically, Boon (2020) suggested that an understanding of the neuroscience of ADHD will enhance understanding of students with ADHD and why they behave differently than other students. In this present study, in turn, we developed a knowledge translation (KT) activity aimed at increasing teacher knowledge of the brain basis of ADHD, in order to respond to the needs of students with ADHD and help teachers reflect on what is needed to provide this support. Further, we paired the neuroscience information with sharing the lived experience of a person with ADHD, with the goal of capitalizing on the benefits of storytelling for effective KT (Bourbonnais \& Michaud, 2018).

\section{Self-Location}

As shown by other scholars in education research and informed by Indigenous research methodologies, there are benefits to the researcher explicitly identifying their positionality and approach to research (Gillies et al., 2014). In recognition of the value of this practice, Kathryn Isenor, the lead researcher, completed a self-location for this study, as follows:

I am an undergraduate researcher who was diagnosed with ADHD in my third year of university. I experienced the difficulty of ADHD during childhood without diagnosis and without the assistance that accompanies it. This research is significant to me as an individual with ADHD because I know what it feels like to be an inconvenience in a 
classroom. When I learned that there was a brain-based explanation for my experience, it changed the way I saw myself.

The better I understand ADHD, the better I can deal with it, which goes the same for people around me. This research is beneficial because merely knowing that there is a brain basis for these differences helped me, and I think it has helped others. As a student with ADHD, I was not intentionally disruptive or trying to make things hard for my teachers and classmates. I now know that children with ADHD can be intimidating and frustrating for educators because of the added complication of behaviour management, but I was never trying to be a difficult student. By improving understanding of ADHD, we can enhance interactions between students with ADHD and their teachers and hopefully make the classroom better for everyone involved. This research is so important to me because I want teachers to be considerate and understanding in their interactions with all their students, neurotypical or not. This knowledge translation research could impact so many students' lives.

\section{Literature Review}

Teachers are often ambivalent and unconvinced about the legitimacy of ADHD diagnoses and the brain basis of ADHD (Boon, 2020). Evidence shows that teachers with more knowledge of ADHD in general (symptoms, diagnosis, treatment) display less stigma towards students with ADHD (Toye et al., 2019). As well, descriptions of the biological explanation of ADHD reduce social distance between educators and their students (Lebowitz et al., 2012). Further, storytelling can enhance knowledge translation (Bourbonnais \& Michaud, 2018). Thus, we chose to incorporate the lived experience of a person with ADHD into our KT activity. The main intention of this KT activity was to challenge ambivalent attitudes among teachers and reduce stigma surrounding ADHD by providing evidence of its brain basis (Haslam \& Kvaale, 2015; Loughman \& Haslam, 2018; Toye et al., 2019). We posit that by combining the brain content and personal story, we created an interesting, informative, and effective KT activity for educators.

While students with ADHD can present challenges to schools and classrooms, we propose that neurodiversity can also afford certain strengths and benefits to classroom environments. Equipping classroom teachers with neurodiverse perspectives can assist them in accessing the strengths and abilities of all students within inclusive classroom settings (Rentenbach et al., 2017). Often, students with ADHD who have adequate cognitive and interpersonal skills are able to find success in social and academic tasks, but it is their impulsivity and inattention to detail that may impact performance (Climie et al., 2017). Research exploring strengths of students with ADHD is limited (but see Hoogman et al., 2020), thus adopting a strength-based approach to ADHD is a worthwhile research endeavor (Climie \& Mastoras, 2015). Thus, we explored a method of describing the neuroscience of ADHD, while centering a student with lived experience as the expert in delivering this information.

\section{Building Educator Competency Through KT}

$\mathrm{KT}$ is a process for changing attitudes and building understanding, which involves taking evidence borne from scientific research and translating it into consumable knowledge for a relevant audience (Davis et al., 2003), and bridging the gap between research and practice (Bennett et al., 2016). Despite its critical importance for enabling evidence-based practice, little research has looked into effective strategies for KT (Bourbonnais \& Michaud, 2018; Zhao et al., 
2020).

Teacher professional development (PD) has been well discussed in the extant literature. Participation in PD is associated with improvements in teacher knowledge (Roehrig et al., 2012), self-efficacy in working with individuals with emotional and behavioural challenges (Latouche \& Gascoigne, 2017), and more positive teacher attitudes towards working with students with ADHD (Zentall \& Javorsky, 2007). Quality PD is generally teacher-led, involves discussion of topics that inform teacher practices, is focused on instruction, and is engaging and collaborative (Desimone et al., 2002; Hunzicker, 2011). In contrast, KT is generally researcher-led and empirically based, focused on taking the findings of scientific research and making them accessible to lay audiences. KT has demonstrated efficacy in supporting teachers and students in developing critical thinking and scientific knowledge (Jacque et al., 2013).

Much of the research into KT focuses on healthcare and public health (e.g., Chapman et al., 2020; Zhao et al., 2020). Even in these sectors, research into KT's effectiveness is still an emerging area (Bourbonnais \& Michaud, 2018; Zhao et al., 2020). The use of research to inform evidence-based practice is less well-established in education compared to medicine (HemsleyBrown \& Sharp, 2003). Previous KT studies targeting educators have been focused on increasing competency in topics such as diabetes (Nichols \& Norris, 2002), concussion (Provvidenza et al., 2019), and eating disorders (McVey et al., 2009).

Research on ADHD-related KT activities for teachers is limited. Past research has demonstrated that teacher knowledge about ADHD can be improved through participation in KT activities (Barnett et al., 2012). Barnett et al. (2012) used a web-based intervention for a 7-week knowledge translation activity which resulted in teachers' knowledge about ADHD positively changing. To our knowledge, there are no previous research studies investigating the effectiveness of combining a personal story with neuroscience research for educator KT.

\section{KT Activity Content}

Our research team developed a KT activity to share current neuroscience findings as they relate to ADHD, combined with the lived experience of having ADHD. The content included in the KT activity is summarized below.

\section{Neuroscience}

The neuroscience content was based on the work of Kasparek and colleagues (2015), in which many brain imaging studies were reviewed. Many brain-based factors may have a role in the presentation of ADHD, including changes in brain shape/size and connectivity between brain regions (Kasparek et al., 2015; Uddin et al., 2017). These changes are correlated with numerous clinical features, including executive dysfunction and co-occurring anxiety. Importantly, the current treatments can improve at least some of these processes in people with ADHD, and treatment-related benefits can be observed both clinically and via neuroscientific methods such as brain scans (Kasparek et al., 2015). Brain development trajectory is also different between children with ADHD and typically developing children (Shaw et al., 2007).

It is important to note that these brain differences do not always represent impairments, but rather may simply be differences. These functional differences vary from person to person, and individuals with ADHD can be high achieving and successful despite these differences (APA, 2013). As such, the KT activity described these brain differences in order to reduce stigma, and to help teachers better understand the mechanism of effective accommodations. 
The notion of celebrating differences, rather than focusing on deficits, is related to the concept of neurodiversity. Neurodiversity refers to the ways in which different brains receive, interpret, and respond to social and environmental cues, resulting in different manifestations of behaviour. Neurodiversity was originally conceptualized and discussed by activists and researchers of autism spectrum disorder (ASD; den Houting, 2019), but has expanded to apply to other neurodevelopmental disorders such as ADHD and specific learning disorders (Armstrong, 2015; Sonuga-Barke \& Thapar, 2021). A neurodiversity paradigm shifts the conversation from the student as having a disability, to an examination of the classroom environment as a disabling context where the student's success is limited due to its lack of hospitality, accommodation, or consideration (den Houting, 2019). Framing ADHD as an example of neurodiversity allows for teachers to consider not only the functional deficits experienced by students with ADHD, but also the complementary strengths and abilities. This further allows teachers to consider not only the accommodations that are required for students with ADHD, but also how an inclusive classroom can help students with ADHD to reach their full potential.

\section{Personal Story}

The following is a summary of Kathryn's personal story that was included as part of the KT activity.

My experience with ADHD was as unique to me as anyone else with the diagnosis. As a child, I was enthusiastic and successful in school and a very quick learner. I was also easily distracted and constantly disruptive. Because I had a high reading level, teachers would often give me books to read to the class in order to keep me occupied. I struggled when I moved from elementary to secondary school because I had been given more attention and special treatment in elementary. As I progressed, school was less interesting because I was given the same amount of work as everyone else, so I got bored and would read in class or distract my friends. In high school, my priorities shifted and my attendance got worse. I rarely completed assignments, but I was still excelling on tests. As a child, I displayed many ADHD symptoms but fell through the cracks - maybe because I was a girl, or maybe because my grades were fine.

In university, I lost all structure and things got worse. There were no repercussions for missing class or skipping assignments, so I did both regularly. Despite feeling like I was underperforming and failing, I could not push myself to get things done. After failing my first year and coming back on academic probation, I worked hard to stay afloat and come back from such a terrible year. In my third year, a university counsellor suggested that a lot of my struggles sounded like ADHD and she recommended I get tested. I was diagnosed that summer. Finally, it all clicked. I was not experiencing the same thing as my peers and simply doing worse, my brain is different. I cannot do the same thing and expect the same results because my brain is not the same. In my fourth year, I had support from the school, I had strategies to accommodate the differences in my learning abilities, but most importantly, I knew that there was not anything worse about me, I was just different. With the accommodations in place, I improved my grades enough to be accepted as an honours student (with special permission from the chair of psychology and the dean) and was able to do work I was proud of, finally feeling like I was meeting my potential. ADHD is not "solved" for me, but by understanding my brain and the fact that it is different, I am able to manage my symptoms and be kind to myself when I cannot operate like a neurotypical individual. 


\section{Research Objectives}

Using current neuroscience research, our study sought to expand educators' existing knowledge of ADHD by discussing the brain basis of ADHD. By understanding the biological explanation for ADHD, educators can recognize why symptoms occur and better understand their students who are not neurotypical (Boon, 2020). We also integrated a personal experience with ADHD in order to help participants connect with the material. We sought to identify and challenge preconceived notions of ADHD among teachers and enhance understanding by explaining the brain science behind the symptoms of ADHD. We hypothesized that participation in our KT activity would shift teachers' attitudes away from social explanations (e.g., ADHD is a result of poor discipline), towards accepting neuroscientific explanations of ADHD.

\section{Methods}

This study utilized an action research framework to develop and refine the KT activity. Action research is a "sequence of self-reflective, ongoing cycles" (Bennett et al., 2016), meaning that the research is actively reflected on and revised as necessary. Action research is a critical method that intends to create and inspire change to a system. In the current study, the cycles of action research included the "reflect" phase (reflecting on what might need to develop or change), the "plan" phase (planning for change), the "act" phase (acting to bring about change), and the "observe" phase (evaluating the resulting change), then returning to reflection in the following cycle (Kemmis \& McTaggart, 1988; Bennett et al., 2016). We planned three cycles for our study. For each cycle, we considered our own observations as well as the feedback from participants in order to plan and implement improvements for the next cycle.

The research team was led by Kathryn, an undergraduate student researcher, who has lived experience with ADHD. The research was supervised by professors from divergent disciplines. Erin Mazerolle is an assistant professor specializing in neuroscience. Conor Barker is an assistant professor and registered psychologist, with expertise in special education and inclusive classroom practices. The research team met for weekly meetings throughout the action research process as part of Kathryn's honours thesis in psychology.

\section{Participants}

The first cycle was delivered as a pilot to the research supervisors. The second cycle was delivered to a class of 19 graduate students in a Master of Education Inclusive Education class. The third cycle was an open public presentation targeted at teachers with 29 participants. Participants of the third cycle were recruited from social media, email, and word of mouth.

\section{Measures}

Participants were invited to participate in pre-activity and postactivity surveys. Across the latter two cycles, 41 participants completed the preactivity survey and 22 completed the post activity survey. Of our preactivity survey respondents, $42.5 \%$ were in-service teachers and $2.5 \%$ were preservice teachers. The remaining participants reported being either former teachers, individuals that worked with students in other capacities (student advising, educational assistant, community support worker, etc.), or did not state their occupation. The average (standard deviation) years of teaching experience among survey respondents was 10.6 (7.8) years with a range of 0 to 29 years.

The preactivity and postactivity surveys also asked participants to share experiences and strategies for aiding students with ADHD. Vignettes developed by Lebowitz and colleagues 
(2012) were used to describe a student with ADHD without stating the diagnosis and attitudes were measured about this vignette (e.g., "To what extent is disruptive behavior the student's fault?"). The same attitudes were then measured in questions that specifically referred to a student with ADHD. The survey also asked participants to rate the degree to which ADHD symptoms are attributable to social factors and brain factors. Questions about attitudes were measured on a Likert scale that ranged from 1 (not at all) to 9 (completely). See Table 1 for the specific text used for the questions. The post-activity survey additionally asked participants to share their major take-aways and provide general feedback on the KT activity. The goal of the surveys was to compare attitudes about ADHD before and after the knowledge translation. We were also interested in teacher strategies for supporting children with ADHD to see if there was already knowledge in place of how to help these students.

\section{Data Collection and Analysis}

In addition to the preactivity and postactivity surveys (see description above in Measures section), an audit trail of the action research cycles was also completed (Wolf, 2003) which include collected items such as a personal journal on the process and progress of the activity development, feedback from the research supervisors, and minutes from all research meetings. Preactivity and postactivity differences in responses to survey questions about attitudes were compared using a Wilcoxon signed-rank test in SPSS 26. Qualitative data were summarized using a simplified thematic analysis (Braun \& Clarke, 2006).

\section{Results}

\section{Summary of the KT Activity}

The KT activity covered Kathryn's personal experience with ADHD, discussed a number of brain content topics surrounding ADHD, and closed with a discussion about neurodiversity that was linked back to the personal experience. Some specific content included challenging ADHD myths, explaining executive functioning, and comparing neurotypical brain development to brain development in children with ADHD.

\section{Quantitative Results}

Across both Cycles 2 and 3, 14-16 participants answered the questions about attitudes towards ADHD on both the preactivity and postactivity surveys, depending on the question. Given the small sample size, we opted to combine the quantitative data from both cycles. Wilcoxon signed-rank tests showed no significant differences between preactivity and postactivity ratings for any of the survey questions $(\mathrm{p}>.05)$. However, all questions trended toward a change in attitude in which participants placed less blame on individuals with ADHD and rated ADHD as more attributable to neurological factors than social factors post-activity. Figure 1 shows the mean responses to the Likert scale survey questions preactivity and postactivity, with error bars representing standard error. The text of the questions can be found in Table 1. Lower numbers represent assigning less blame to individuals with ADHD and/or greater belief in the brain basis of ADHD ( $p>.05$ for all questions, Wilcoxon sign-rank tests). Table 1 provides the questions that were asked of the participants.

\section{Figure 1}

Mean Responses to the Likert Scale Survey Questions Preactivity and Postactivity 


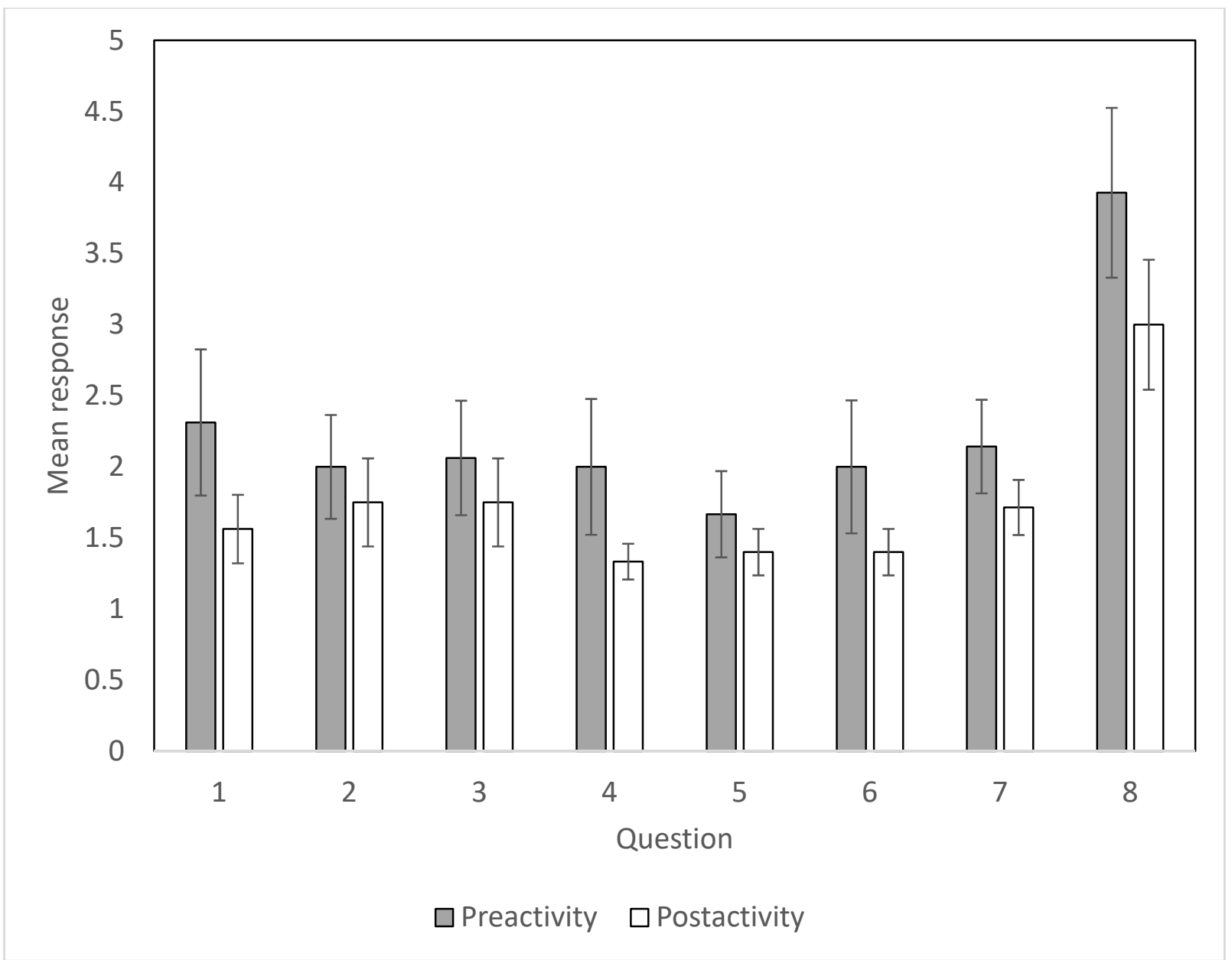

Note. The text of the questions can be found in Table 1. Lower numbers represent assigning less blame to individuals with ADHD and/or greater belief in the brain basis of ADHD. N=14-16 depending on the question ( $p>.05$ for all questions, Wilcoxon sign-rank tests). Error bars represent standard error.

\section{Table 1}

Questions From the Likert Scale Survey Questions Preactivity and Postactivity (from Lebowitz et al., 2012, used with permission)

\section{Vignette for questions 1-3.}

Andrew is an 8-year-old boy who has been having some difficulties both in school and at home. In class, he often has difficulty staying focused and paying attention. He fidgets and squirms in his seat constantly, and the teacher often has to repeat directions for him multiple times. He becomes easily distracted, missing details, and forgetting to turn in homework assignments. While the rest of the children are quietly working, Andrew is often up and out of his seat, roaming around the classroom. At home, Andrew is often impatient and often is unable to control his emotions. He becomes bored with tasks easily and frequently interrupts his parents' conversations and activities.

Question $1 \quad$ Suppose that Andrew receives the treatment that is standard for problems like his but no improvement occurs. To what extent is this due to Andrew's lack of selfdiscipline or willpower? 


\begin{tabular}{ll}
\hline Question 2 & $\begin{array}{l}\text { Suppose that other children who sit near Andrew in class are distracted by } \\
\text { Andrew's behavior, which negatively impacts their learning. To what extent should } \\
\text { Andrew be reprimanded or punished? }\end{array}$ \\
\hline Question 3 & $\begin{array}{l}\text { Suppose that Andrew is failing in school. To what extent is this due to Andrew's } \\
\text { lack of self-discipline or willpower? }\end{array}$
\end{tabular}

\section{Prompt for questions 4-8.}

Consider a student that has a diagnosis of Attention Deficit Hyperactivity Disorder (ADHD).

\begin{tabular}{ll}
\hline Question 4 & $\begin{array}{l}\text { Suppose the student receives the treatment that is standard for ADHD but does not } \\
\text { improve. To what extent is this due to the student's lack of self-discipline or } \\
\text { willpower? }\end{array}$ \\
\hline Question 5 & $\begin{array}{l}\text { Suppose that other children who sit near the student in class are distracted by their } \\
\text { behavior, which negatively impacts their learning. To what extent should that } \\
\text { student be reprimanded or punished? }\end{array}$ \\
\hline Question 6 & $\begin{array}{l}\text { Suppose the student is failing in school. To what extent is this due to their lack of } \\
\text { self-discipline or willpower? }\end{array}$ \\
\hline Question 7 & $\begin{array}{l}\text { To what degree do you attribute ADHD symptoms to the brain? (Note: responses to } \\
\text { this question were reverse coded for the purposes of the graph) }\end{array}$ \\
\hline To what degree do you attribute ADHD symptoms to social factors? (e.g., parental \\
discipline)
\end{tabular}

\section{Qualitative Emergent Themes}

Eighteen participants across Cycles 2 and 3 completed postactivity survey questions which were used for the simplified thematic analysis. The findings for each theme we identified are described below.

\section{Activity Design}

Our study found a few points of interest regarding the design of the activity. First, we found that the participants required the language of the activity to be accessible and understandable within their context. Much of the language and vocabulary used in neuroscience is not typical day-to-day vernacular for preservice and in-service teachers. Terms such as volume reduction, cortical maturation, and frontostriatal dysfunction require some form of introduction or contextualization in order to be understood and valuable among the teacher participants. As we simplified the language used to communicate complex neuroscience topics, we noticed an increase in the number of comments from participants suggesting improved retention of the neuroscience content.

Further, we found that the participants benefited from an opportunity to discuss and engage with each other about the content as part of the KT activity. As one participant indicated in the feedback form, the activity could be improved with:

Longer time in the break out or a facilitator that provides more opportunity for the group to speak. Less questions to discuss in the breakout room, seemed to [sic] big to get to the heart of the discussion in the time allotted.

Even in short KT activities, teachers strongly value the opportunity to discuss with peers their thoughts and reflections as it comes to teaching and teaching practice, even with teaching 
peers they have not previously met before.

\section{Teachers' Needs and Strategies}

When looking at the needs and strategies of teachers, we found that participants identified many strategies for working with children with ADHD. Participants in the second cycle (graduate students in a Master of Education Inclusive Education class) were able to identify five types of interventions: behaviour management (e.g., body breaks), student engagement (e.g., allowing them to integrate their interests), academic adaptations (e.g., allowing them to be graded on different types of assignments), teacher behaviour (e.g., maintaining communication with students' guardians), and environmental accommodations (e.g., different seating arrangements). In the third cycle (public), participants identified strategies from the following categories: behaviour management, teacher behaviour, workload management (e.g., chunking up assignments), and inclusivity (e.g., assignments that allow multiple grading options). Despite identifying several strategies, multiple participants indicated they wished that additional strategies were explored as part of our activity. For example, one participant stated that they felt more time should have been spent on strategies, suggesting "A bit more of what teachers can do in the classroom" would be useful going forward. Our presentation did not specifically include strategies for teachers, but it indirectly provided neuroscientific explanations for why strategies are needed or why they may be effective.

The apparent contradiction of knowing many strategies and still wanting more suggests that teachers may not have a working knowledge of how these strategies can assist children with ADHD in being more successful in the classroom, or how to implement the strategies effectively. A discussion of strategies Kathryn has personally used to manage ADHD was also included in the KT activity. One participant stated that this content expanded the way they think about ADHD management: "I have moved from thinking only about classroom accommodations, pediatrician referrals etc. to what do students need to be successful once they have completed school and need to exist as a successful citizen."

\section{Role of Sharing Personal Experience Within Knowledge Translation}

We made numerous observations related to the inclusion of personal experience in the KT activity. First, the method used to personalize the presentation was affected by the online nature of the delivery of the activity. Pictures of Kathryn as a child attending elementary school, and the use of artifacts such as her university transcripts helped to illustrate her personal story and allowed participants to better link it to their own students. From the activity, Kathryn shared:

I was diagnosed that summer. Finally, it all clicked, I wasn't experiencing the same thing as my peers and simply worse, my brain is different. I can't do the same thing and expect the same results because my brain is not the same.

Near the end of the activity, during a story about Kathryn's grandfather and the benefits of neurodiversity, more childhood photos were included as well as one with her grandfather. From the activity, Kathryn shared:

He was passionate, full of life, hard-headed and loved for who he was. He was praised for the things that would have labelled him as having a disorder, and if that doesn't show what a strength neurodiversity can be, I'm not sure what else to tell you.

These features of the presentation increased personalization to counter the depersonalized nature of online presentations. 
A major focus of the personal aspect of the presentation was to emphasize the individual differences and unique experiences of those with ADHD. For example, Kathryn linked her own experience of a relatively late diagnosis to gender differences in ADHD diagnosis rates and symptoms. This difference was something that connected with the participants, as one stated: "It was powerful to hear a first-hand account of ADHD in females." One participant stated: "I appreciated hearing the info/story from someone with the 'lived experience.' Much more powerful and effective, as compared to reading from an article/book."

\section{Benefits of Brain Content}

The delivery of the neuroscience of ADHD was a crucial aspect of our study. This component benefitted the most from the iterative process of the action research methodology we used. One example of this is an improvement to our discussion of typical brain development compared to brain development in those with ADHD. In our second cycle, which was delivered to graduate students, one participant asked about the difference between typical executive functioning development of adolescents and the executive functioning impairment of ADHD. We speculated that teachers may tend to contextualize their knowledge of children with ADHD via comparisons with typically developing children. In the following cycle, we expanded on this content by including a video comparing brain maturation in typical children and children with ADHD. Another point of the presentation that benefitted from multiple iterations was the topic of neurodiversity. We alluded to neurodiversity in early versions of the presentations and expanded on it greatly in the final presentation. Discussing the benefits of neurodiversity can counter some of the negative connotations of the word "disorder," as well as the negative experiences teachers may have had in the past. While categorization is useful for understanding and adaptation, it can also marginalize individuals in a way that ignores potential strengths they have due to their differences.

As well as giving our participants a greater understanding of their neurodiverse students, this study intended to use the explanation of neuroscience to destigmatize ADHD and reduce the emphasis on the social determinants of ADHD (e.g., poor parenting). Teacher professional development discourses regarding ADHD are often more focused on reducing disruptive symptoms rather than the disabling classroom environment. A shift towards improving inclusivity in the classroom could help students with ADHD flourish and find success.

\section{Discussion}

This study used action research methodology to develop a KT activity for educators on the neuroscience of ADHD. Our work was novel in that we included a personal story from an individual with ADHD in the KT activity. Participants reported connecting with the personal story. We also observed a non-significant shift in attitudes among our participants, towards assigning less blame to students with ADHD and attributing ADHD symptoms more to the brain than social factors.

\section{Knowledge Translation Activity Effectiveness}

We reached 48 educators in the final two cycles. The most consistent feedback received was appreciation of the personal story and recognition of the differences among individuals with ADHD. Many of the major take-aways from the survey and discussions were facts about ADHD that were directly connected to the personal aspects of the presentation. Some of these were individual differences and appreciation of our message of hope for students with ADHD. 
Another major take-away was that our participants were not aware of the differences in presentation of ADHD in girls. Girls tend to be underdiagnosed in part because ADHD is more common in boys and so people do not look for it in girls (Quinn \& Madhoo, 2014). As well, girls tend to present more often with inattentive symptoms rather than hyperactive symptoms which get more notice (Quinn \& Madhoo, 2014).

Another interesting finding was that while our participants identified several strategies that can support students with ADHD, they continued to solicit additional strategies. The purpose of our KT activity was to review the neuroscience to help teachers understand how and why these strategies work rather than to expand teacher strategies that they already know and are using. Neuroscience knowledge may help teachers implement the strategies more effectively in the classroom as it provides them with a scientific understanding about how they are used not to manage student behaviour but rather to increase a child's performance potential. This, in turn, shifts teachers' perspectives towards understanding, accepting, and valuing the contributions neurodiverse students bring.

\section{Action Research for Developing a Knowledge Translation Activity}

Action research was an effective method to develop this KT activity. Multiple cycles were performed, allowing for reflection and enhancement with each iteration. Improvement in the quality of the activity took place over the course of the research in a structured, documented manner. Over the course of development, the action research approach changed this activity to enhance the personal aspect. It also provided multiple opportunities to reflect on and refine the brain content.

The research team included experts in both neuroscience and education. By combining these areas of expertise, we were able to better serve the target audience of preservice and inservice teachers. We found that the iterative nature of the action research method, which provided multiple opportunities to integrate the expertise from both fields, was a highly effective collaborative approach.

\section{Value of Self-Location and Sharing the Personal Story}

Self-location is the practice of identifying yourself and your perspective within the research (Gillies et al., 2014). Kathryn used self-location to gain awareness of her perspective and to share it explicitly. Through self-location, she identified herself within the study and provided context. This practice helped the research team value the personal experiences shared and recognize the benefits in acknowledging the role of those experiences in motivating and informing the research process.

In fact, we found that inclusion of the personal story was a major strength of the KT activity we developed. From the qualitative data, feedback was consistent in the appreciation of the personal story. The "major take-aways" reported by participants were directly connected to the personal story shared (e.g., the uniqueness of ADHD presentation among individuals, the strength of embracing neurodiversity). The questions asked by participants during the final question period were mostly personal rather than general or focused on brain content. It was inspiring to observe that participants connected with the material through the personal story. This observation was consistent with previous evidence for the effectiveness of storytelling for KT (Bourbonnais \& Michaud, 2018).

\section{Interdisciplinary Challenges and Opportunities}


This research was developed by a team of researchers each bringing their own experiences and expertise to develop the best possible KT activity. Interdisciplinary research brings both challenges and opportunities and was a great strength to this work. A neuroscientist is essential in order to present accurate and relevant neuroscientific information to our participants. However, the work that is done in neuroscience is a very different style to the more qualitative nature of this research. Evaluation of KT greatly benefits from qualitative perspectives, which allow deeper insight into the impacts of the activity than a Likert-style survey could ever provide.

\section{Limitations}

Due to the ongoing global pandemic, our KT activity had to be presented online. Both the activity and the survey participation may have been impacted by the online format. An in-person presentation would have been preferred because the personal story may have been more impactful. If surveys were distributed in person following the activity, we may have achieved a better response rate.

Participants may have had more positive or neutral attitudes about ADHD or brain science at baseline than the larger population because the activity was advertised as a presentation about ADHD and the brain. This may have played a part in the lack of significant attitude changes, because participants may have entered the study with higher-than-average positive attitudes about ADHD (Zentall \& Javorsky, 2007).

Our results indicated a trend toward a change in teacher attitudes, but did not necessarily result in any change in teacher practice. Similar limitations have also been reported by previous studies in that we may have improved teacher self-efficacy and knowledge, but we may not have made a change in teacher practices (Barnett et al., 2012; Blotnicky-Gallant et al., 2014; Latouche \& Gascoigne, 2017; Zentall \& Javorsky, 2007). We recognize, however, that our goal was not necessarily to change teacher practice, but rather to explore the outcomes of combining neuroscience with the use of personal story.

Finally, due to the COVID-19 pandemic, our KT activity was delivered in an online format, which provided both opportunities and challenges. One opportunity was that we were able to deliver our activity to teachers and members of the public across Canada during our third cycle. We also were able to record our session for others to view on their own time. Some participants had limited opportunity to participate due to poor internet connectivity, particularly among rural participants. To accommodate participants with poor internet connectivity, we opted not to include a video of the presenter, which likely had the effect of reducing personal connections made between the presenter and the audience. We also had a low response rate to our survey, with only $37.5 \%$ of participants having completed the surveys.

\section{Areas of Future Work}

While the ongoing global pandemic did provide a complication in terms of how the activity would be ideally presented, the online format may be ideal for distributing the KT activity more broadly. Future efforts will be made to create a video with this presentation to make it available to more people. This format will limit audience participation and interaction but will also improve accessibility. One way of simulating the audience participation aspect could be to include an intermission in which the participants are asked questions about the topic. This could provide that opportunity for reflection in the asynchronous online setting that the discussion 
groups were attempting to achieve.

While the KT activity in our final cycle included content on the benefits of neurodiversity in general and related anecdotes from Kathryn's life, future iterations could include more research results related to the positive aspects of ADHD. This is still an emerging area of research, although there is some evidence from meta-analysis that subclinical ADHD is associated with enhanced divergent thinking relative to both typically developing individuals and individuals with clinical ADHD (Hoogman et al., 2020). As this research continues to evolve, our important message of the benefits of neurodiversity can be refined.

This research could serve as a template for combining personal lived experience and neuroscience for KT activities on other neurodevelopmental disorders, such as ASD, specific learning disability, or intellectual disability. More teacher education on the brain basis of these disorders could improve the classroom environments for all kinds of neurodivergent students.

\section{Conclusion}

In conclusion, this study found that action research methodology applied to knowledge translation was effective for developing a KT activity to educate teachers on the brain basis of ADHD. We found that many participants reported connecting with the personal experience content, suggesting that combining lived experience and neuroscience content may be a powerful approach for future KT efforts. 


\section{References}

American Psychiatric Association (APA). (2013). Diagnostic and statistical manual of mental disorders (5th ed.) https://doi.org/10.1176/appi.books.9780890425596

Armstrong, T. (2015). The myth of the normal brain: Embracing neurodiversity. AMA Journal of Ethics, 17(4), 348-352. https://doi.org/10.1001/journalofethics.2015.17.4.msoc1-1504

Barnett, B., Corkum, P., \& Elik, N. (2012). A web-based intervention for elementary school teachers of students with attention-deficit/hyperactivity disorder (ADHD). Psychological Services, 9(2), 227-230. https://doi.org/10.1037/a0026001

Bennett, S., Whitehead, M., Eames, S., Fleming, J., Low, S., \& Caldwell, E. (2016). Building capacity for knowledge translation in occupational therapy: Learning through participatory action research. BMC Medical Education, 16(1), 257. https://doi.org/10.1186/s12909-0160771-5

Blotnicky-Gallant, P., Martin, C., McGonnell, M., \& Corkum, P. (2015). Nova Scotia teachers' ADHD knowledge, beliefs, and classroom management practices. Canadian Journal of School Psychology, 30(1), 3-21. https://doi.org/10.1177/0829573514542225

Boon, H. (2020). What do ADHD neuroimaging studies reveal for teachers, teacher educators and inclusive education? Child \& Youth Care Forum, 49. https://doi.org/10.1007/s10566019-09542-4

Bourbonnais, A., \& Michaud, C. (2018). Once upon a time: Storytelling as a knowledge translation strategy for qualitative researchers. Nursing Inquiry, 25(4), e12249. https://doi.org/10.1111/nin.12249

Braun, V., \& Clarke, V. (2006). Using thematic analysis in psychology. Qualitative Research in Psychology, 3(2), 77-101. https://doi.org/10.1191/1478088706qp063oa

Chapman, E., Haby, M. M., Toma, T. S., de Bortoli, M. C., Illanes, E., Oliveros, M. J., \& Barreto, J. O. M. (2020). Knowledge translation strategies for dissemination with a focus on healthcare recipients: An overview of systematic reviews. Implementation Science: IS, 15(1), 14. https://doi.org/10.1186/s13012-020-0974-3

Climie, E. A., Saklofske, D. H., Mastoras, S. M., \& Schwean, V. L. (2017). Trait and ability emotional intelligence in children with ADHD. Journal of Attention Disorders, 23(13), 1667-1674. https://doi.org/10.1177/1087054717702216

Climie, E., \& Mastoras, S. (2015). ADHD in schools: Adopting a strengths-based perspective. Canadian Psychology/Psychologie Canadienne, 56, 295-300. https://doi.org/10.1037/cap0000030

Davis, D., Davis, M. E., Jadad, A., Perrier, L., Rath, D., Ryan, D., Sibbald, G., Straus, S., Rappolt, S., Wowk, M., \& Zwarenstein, M. (2003). The case for knowledge translation: Shortening the journey from evidence to effect. BMJ, 327(7405), 33-35. https://doi.org/10.1136/bmj.327.7405.33

den Houting, J. (2019). Neurodiversity: An insider's perspective. Autism, 23(2), 271-273. https://doi.org/10.1177/1362361318820762

Desimone, L. M., Porter, A. C., Garet, M. S., Yoon, K. S., \& Birman, B. F.. (2002). Effects of 
professional development on teachers' instruction: Results from a three-year longitudinal study. Educational Evaluation and Policy Analysis, 24(2), 81-112. https://doi.org/10.3102/01623737024002081

Gillies, C., Burleigh, D., Snowshoe, A., \& Werner, D. (2014). Walking in circles: Self-location in Indigenous youth violence prevention research. First Nations Perspectives Journal, 6(1), 5-25. https://mfnerc.org/wp-content/uploads/2014/10/Walking-in-Circles.pdf

Haslam, N., \& Kvaale, E. P. (2015). Biogenetic explanations of mental disorder: The mixedblessings model. Current Directions in Psychological Science, 24(5), 399-404. https://doi.org/10.1177/0963721415588082

Hemsley-Brown, J., \& Sharp, C. (2003). The use of research to improve professional practice: A systematic review of the literature. Oxford Review of Education, 29(4), 449-471. https://doi.org/10.1080/0305498032000153025

Hoogman, M., Stolte, M., Baas, M., \& Kroesbergen, E. (2020). Creativity and ADHD: A review of behavioral studies, the effect of psychostimulants and neural underpinnings.

Neuroscience \& Biobehavioral Reviews, 119, 66-85. https://doi.org/10.1016/j.neubiorev.2020.09.029

Hunzicker, J. (2011). Effective professional development for teachers: A checklist. Professional Development in Education, 37(2), 177-179. https://doi.org/10.1080/19415257.2010.523955

Jacque, B., Malanson, K., Bateman, K., Akeson, B., Cail, A., Doss, C., Dugan, M., Finegold, B., Gauthier, A., Galego, M., Roundtree, E., Spezzano, L., \& Meiri, K. F. (2013). The Great Diseases Project: A partnership between Tufts Medical School and the Boston public schools. Academic Medicine: Journal of the Association of American Medical Colleges, 88(5), 620-625. https://doi.org/10.1097/ACM.0b013e31828b50fb

Kasparek, T., Theiner, P., \& Filova, A. (2015). Neurobiology of ADHD from childhood to adulthood: Findings of imaging methods. Journal of Attention Disorders, 19(11), 931-943. https://doi.org/10.1177/1087054713505322

Kemmis, S. \& McTaggart, R. (1988). The action research planner. Deakin University Press

Latouche, A. P., \& Gascoigne, M. (2017). In-service training for increasing teachers' ADHD knowledge and self-efficacy. Journal of Attention Disorders, 23(3), 270-281. https://doi.org/10.1177/1087054717707045

Lebowitz, M. S., Rosenthal, J. E., \& Ahn, W. (2012). Effects of biological versus psychosocial explanations on stigmatization of children with ADHD: Journal of Attention Disorders. https://doi.org/10.1177/1087054712469255

Loughman, A., \& Haslam, N. (2018). Neuroscientific explanations and the stigma of mental disorder: A meta-analytic study. Cognitive Research: Principles and Implications, 3(1), 43. https://doi.org/10.1186/s41235-018-0136-1

McVey, G., Gusella, J., Tweed, S., \& Ferrari, M. (2009). A controlled evaluation of web-based training for teachers and public health practitioners on the prevention of eating disorders. Eating Disorders, 17(1), 1-26. https://doi.org/10.1080/10640260802570064

Nichols, P. J., \& Norris, S. L. (2002). A systematic literature review of the effectiveness of 
diabetes education of school personnel. The Diabetes Educator, 28(3), 405-414. https://doi.org/10.1177/014572170202800310

Provvidenza, C. F., Hartman, L. R., Carmichael, J., \& Reed, N. (2019). Does a picture speak louder than words? The role of infographics as a concussion education strategy. Journal of Visual Communication in Medicine, 42(3), 102-113. https://doi.org/10.1080/17453054.2019.1599683

Quinn, P. O., \& Madhoo, M. (2014). A review of attention-deficit/hyperactivity disorder in women and girls: uncovering this hidden diagnosis. The Primary Care Companion for CNS Disorders, 16(3). https://doi.org/10.4088/PCC.13r01596

Rentenbach, B., Prislovsky, L., \& Gabriel, R. (2017). Valuing differences: Neurodiversity in the classroom. Phi Delta Kappan, 98(8), 59-63. https://doi.org/10.1177/0031721717708297

Roehrig, G. H., Michlin, M., Schmitt, L., MacNabb, C., \& Dubinsky, J. M. (2012). Teaching neuroscience to science teachers: Facilitating the translation of inquiry-based teaching instruction to the classroom. CBE Life Sciences Education, 11(4), 413-424. https://doi.org/10.1187/cbe.12-04-0045

Sciutto, M. J., Terjesen, M. D., \& Frank, A. S. B. (2000). Teachers' knowledge and misperceptions of attention-deficit/hyperactivity disorder. Psychology in the Schools, 37(2), 115-122. https://doi.org/10.1002/(SICI)1520-6807(200003)37:2<115::AIDPITS3>3.0.CO;2-5

Shaw, P., Eckstrand, K., Sharp, W., Blumenthal, J., Lerch, J. P., Greenstein, D., Clasen, L., Evans, A., Giedd, J., \& Rapoport, J. L. (2007). Attention-deficit/hyperactivity disorder is characterized by a delay in cortical maturation. Proceedings of the National Academy of Sciences of the United States of America, 104(49), 19649-19654. https://doi.org/10.1073/pnas.0707741104

Sonuga-Barke, E., \& Thapar, A. (2021). The neurodiversity concept: Is it helpful for clinicians and scientists? The Lancet Psychiatry, 8(7), 559-561. https://doi.org/10.1016/S2215$\underline{0366(21) 00167-X}$

Statistics Canada (2019). Are mental health and neurodevelopmental conditions barriers to postsecondary access?

https://www150.statcan.gc.ca/n1/en/pub/11f0019m/11f0019m2019005eng.pdf?st=HYcMp_AG

Toye, M. K., Wilson, C., \& Wardle, G. A. (2019). Education professionals' attitudes towards the inclusion of children with ADHD: The role of knowledge and stigma. Journal of Research in Special Educational Needs, 19(3), 184-196. https://doi.org/10.1111/1471-3802.12441

Uddin, L. Q., Dajani, D. R., Voorhies, W., Bednarz, H., \& Kana, R. K. (2017). Progress and roadblocks in the search for brain-based biomarkers of autism and attentiondeficit/hyperactivity disorder. Translational Psychiatry, 7(8), e1218. https://doi.org/10.1038/tp.2017.164

Vasiliadis, H.-M., Diallo, F. B., Rochette, L., Smith, M., Langille, D., Lin, E., Kisely, S., Fombonne, E., Thompson, A. H., Renaud, J., \& Lesage, A. (2017). Temporal trends in the prevalence and incidence of diagnosed ADHD in children and young adults between 1999 and 2012 in Canada: A data linkage study. The Canadian Journal of Psychiatry, 62(12), 
818-826. https://doi.org/10.1177/0706743717714468

Wesney, M. (2020). Qualitative case study of teachers' knowledge and use of ADHD-specific interventions (Publication No. 2020-31774-251). [Doctoral Dissertation, North Central University] ProQuest Information \& Learning.

Wolf, Z. R. (2003). Exploring the audit trail for qualitative investigations. Nurse educator, 28(4), 175-178. https://doi.org/10.1097/00006223-200307000-00008

Zentall, S. S., \& Javorsky, J. (2007). Professional development for teachers of students with ADHD and characteristics of ADHD. Behavioral Disorders, 32(2), 78-93. https://doi.org/10.1177/019874290703200202

Zhao, N., Koch-Weser, S., Lischko, A., \& Chung, M. (2020). Knowledge translation strategies designed for public health decision-making settings: A scoping review. International Journal of Public Health, 65(9), 1571-1580. https://doi.org/10.1007/s00038-020-01506-Z 